\title{
Non-target site-based resistance to tribenuron-methyl and essential involved genes in Myosoton aquaticum (L.)
}

\author{
Weitang Liu ${ }^{1 *+} \mathbb{D}$, Shuang Bai ${ }^{1 \dagger}$, Ning Zhao', Sisi Jia², Wei Li ${ }^{1}$, Lele Zhang ${ }^{1}$ and Jinxin Wang ${ }^{1 *}$
}

\begin{abstract}
Background: Water chickweed (Myosoton aquaticum (L.)) is a dicot broadleaf weed that is widespread in winter fields in China, and has evolved serious resistance to acetolactate synthase (ALS) inhibiting herbicides.

Results: We identified a M. aquaticum population exhibiting moderate (6.15-fold) resistance to tribenuron-methyl (TM). Target-site ALS gene sequencing revealed no known resistance mutations in these plants, and the in vitro ALS activity assays showed no differences in enzyme sensitivity between susceptible and resistant populations; however, resistance was reversed by pretreatment with the cytochrome P450 (CYP) monooxygenase inhibitor malathion. An RNA sequencing transcriptome analysis was performed to identify candidate genes involved in metabolic resistance, and the unigenes obtained by de novo transcriptome assembly were annotated across seven databases. In total, 34 differentially expressed genes selected by digital gene expression analysis were validated by quantitative real-time (qRT)-PCR. Ten consistently overexpressed contigs, including four for CYP, four for ATP-binding cassette (ABC) transporter, and two for peroxidase were further validated by qRT-PCR using additional plants from resistant and susceptible populations. Three CYP genes (with homology to CYP734A1, CYP76C1, and CYP86B1) and one ABC transporter gene (with homology to $A B C C 10$ ) were highly expressed in all resistant plants.

Conclusion: The mechanism of TM resistance in M. aquaticum is controlled by NTSR rather than TSR. Four genes, CYP734A1, CYP76C1, CYP86B1, and ABCC10 could play essential role in metabolic resistance to TM and justify further functional studies. To our knowledge, this is the first large-scale transcriptome analysis of genes associated with NTSR in M. aquaticum using the Illumina platform. Our data provide resource for M. aquaticum biology, and will facilitate the study of herbicide resistance mechanism at the molecular level in this species as well as in other weeds.
\end{abstract}

Keywords: Acetolactate synthase, Non-target site-based resistance, Metabolic resistance, RNA-Seq, Tribenuron-methyl, Myosoton aquaticum (L.)

\section{Background}

Herbicide resistance in weeds-which has evolved as an adaptation to herbicide stress-is a global problem threatening crop production. Resistance to herbicides occur via target-site- and non-target site-based resistance mechanisms (TSR and NTSR, respectively). TSR arises from amplification of a target enzyme or structural changes in the herbicide binding site, is widespread in weeds. NTSR

\footnotetext{
* Correspondence: liuwt@sdau.edu.cn; wangjx@sdau.edu.cn

+Weitang Liu and Shuang Bai contributed equally to this work.

${ }^{1}$ Key Laboratory of Pesticide Toxicology and Application Technique, College

of Plant Protection, Shandong Agricultural University, Taian 271018,

Shandong, China

Full list of author information is available at the end of the article
}

minimizes the amount of herbicide that reaches the target site [1-7]. Enhanced herbicide metabolism (i.e., metabolic resistance) by enzymes such as cytochrome P450 (CYP) monooxygenase, glutathione-S-transferase (GST), glycosyltransferase (GT), ATP-binding cassette (ABC) transporter, peroxidase (POD), esterase, and hydrolase contributes to NTSR [1, 3, 8]. Plants may develop metabolic resistance to existing or novel herbicides, posing a major challenge for weed management $[3,8]$.

Acetolactate synthase (ALS)-inhibiting herbicides are applied to a variety of crops worldwide. However, their overuse has resulted in the emergence of resistant weeds. At least 160 weed species are currently known to exhibit resistance to ALS inhibitors, which is more than 
to any other type of herbicide [9]. TSR is the most common mechanism of resistance to ALS inhibitors [7, 10]; to date, at least 28 amino acid substitutions at eight positions (Ala122, Pro197, Ala205, Asp376, Arg377, Trp574, Ser653, and Gly654) of the ALS gene have been identified in various weed species [10, 11]. However, in grass weeds, NTSR is considered as the major mechanism of resistance to ALS and acetyl-coenzyme A carboxylase (ACCase) inhibitors [1], although there are few documented cases among dicot weeds [1, 10].

TSR and NTSR can co-evolve under selective pressure from herbicides; thus, the two mechanisms may coexist in a single species, population, or individual $[12,13]$. Genes involved in metabolic resistance can vary according to species and history of herbicide application [3, 10]; however, in most cases, the underlying genetic mechanisms have not been elucidated.

RNA-sequencing (RNA-Seq) technology has been used to investigate the genetic basis of abiotic stress responses in plants [14, 15], especially in non-model species for which genomic resources are unavailable $[1,16]$. It has also been applied in studies on herbicide resistance in weeds and on genetic differences between resistant and susceptible plants [17]. Genes involved in NTSR to different herbicides have been identified by RNA-Seq in grass weeds such as ryegrass (Lolium rigidum Gaudin) [18-20], black-grass (Alopecurus myosuroides Huds.) [21], American sloughgrass (Beckmannia syzigachne Steud.) [22], shortawn foxtail (Alopecurus aequalis Sobol.) [23], Brachypodium hybridum [24], perennial ryegrass (Lolium perenne) [25], and flixweed (Descurainia sophia L.) [26].

Water chickweed (Myosoton aquaticum (L.)) is a diploid dicot broadleaf weed that is widespread in winter fields in China and has evolved resistance to many ALS inhibitors [27]. Previous studies have reported $A L S \mathrm{mu}-$ tations in $M$. aquaticum, identifying TSR as the major mechanism of herbicide resistance although coexisting NTSR was observed in many populations [28, 29]. Here, we identified a tribenuron-methyl (TM)-resistant population of M. aquaticum (HN10) with no known ALS resistance mutations in surviving individuals. We obtained resistant plants from the HN10 population through two rounds of selection (designated MR) and identified the genes involved in TM resistance by RNA-Seq and quantitative real-time (qRT-)PCR analyses.

\section{Results}

TM dose-response in the absence and presence of malathion

Dose-response studies confirmed that the MR M. aquaticum population showed moderate resistance to TM (6.15-fold higher than $\mathrm{S}$ plants). When malathion was applied at $750 \mathrm{~g} \mathrm{ha}^{-1}$, there was no effect on plant biomass (Table 1 and Fig. 1) in either the $S$ or MR populations; however, the MR population developed sensitivity to TM and the sensitivity of the already susceptible $\mathrm{S}$ population was further enhanced (Table 1 and Fig. 1). Malathion is a CYP inhibitor [30, 31] that has been widely used as a marker of CYP involvement in metabolic resistance to ALS inhibitors [10]. In the present study, treatment with malathion combined with TM increased the sensitivity of the MR population, likely through enhanced metabolism mediated by CYP.

\section{In vitro ALS activity assay and ALS gene sequencing}

ALS activity in the MR and $S$ populations was compared with an in vitro ALS activity assay. There was no difference in ALS gene expression between the two groups, and gene expression could be induced by TM in both populations (unpublished data). In the absence of TM, total ALS activity was lower in extracts from MR as compared to $\mathrm{S}$ plants (11.76 \pm 0.53 vs. $21.78 \pm 1.72 \mu \mathrm{mol}$ acetoin formed $\mathrm{min}^{-1} \mathrm{mg}^{-1}$ protein). Adding TM to the reaction almost completely inhibited ALS activity in both $S$ and MR plants at concentrations $\geq 1.0 \mu \mathrm{M}$ (Fig. 2). The $\mathrm{I}_{50}$ values of $\mathrm{S}$ and MR plants were similar $(0.34 \pm 0.05$ and $0.42 \pm 0.17 \mu \mathrm{M}$, respectively; $P=$ 0.8733) (Table 1). ALS gene sequencing revealed no known $A L S$ resistance mutations in MR plants (GenBank accession nos. of $A L S$ gene sequences for $\mathrm{S}$ and MR are KF589890.1 and MF288558, respectively). Thus, whole-plant resistance in the MR population is not due to a TSR mechanism.

\section{RNA-Seq and de novo assembly}

To obtain a comprehensive set of transcripts for M. aquaticum, a pooled cDNA library of 12 mixed RNA samples from $M$. aquaticum seedlings was analyzed with the Illumina HiSeq 4000 platform. The library generated $603,682,588$ raw reads (Table 2). After quality control and data clean-up, we obtained 551,895,330 clean reads ranging from 44,080,630 to 47,652,304 per sample that were then used for de novo assembly (Table 2 and Additional file 1). The reads were assembled into 182,036 transcripts with an average length of $1121 \mathrm{bp}$; their length distributions are shown in Additional file 2. Up to $94.37 \%$ of sequenced clean reads were mapped back onto the transcripts using Bowtie 2; of these, 101,307 unigenes > $200 \mathrm{bp}$ and 44,649 unigenes $>500$ bp with a mean length of 872 bp and an N50 length of 1650 bp were obtained using the longest transcript at each locus of each gene (Table 2 and Additional file 2). In addition, the Basic Local Alignment Search Tool (BLAST) matched $35.8 \%$ of unigenes to sequences of Arabidopsis thaliana (L.) Heynh., with an average accuracy of $71.56 \%$.

\section{Gene annotation and functional classification}

Unigene annotation was conducted by BLAST searches against seven public databases (Table 3). In total, 44,117 $(43.55 \%)$ unigenes were successfully annotated in at least 
Table $1 \mathrm{GR}_{50}$ and $\mathrm{I}_{50}$ values of the susceptible (S) and resistant (MR) Myosoton aquaticum population for tribenuron-methyl

\begin{tabular}{|c|c|c|c|c|c|c|}
\hline \multirow[t]{2}{*}{ Herbicide } & \multicolumn{3}{|c|}{$\mathrm{GR}_{50}\left(\mathrm{~g} \text { ai ha }{ }^{-1}\right)^{\mathrm{a}}$} & \multicolumn{3}{|l|}{$I_{50}(\mu M)^{b}$} \\
\hline & $S$ & MR & $\mathrm{Rl}^{\mathrm{C}}$ & $\mathrm{S}$ & MR & $\mathrm{Rl}^{\mathrm{c}}$ \\
\hline Tribenuron-methyl & $0.27 \pm 0.09$ & $1.66 \pm 0.72$ & 6.15 & $0.34 \pm 0.05$ & $0.42 \pm 0.17$ & 1.24 \\
\hline Tribenuron-methyl+malathion & $0.16 \pm 0.09$ & $0.30 \pm 0.10$ & 1.88 & - & - & _ \\
\hline
\end{tabular}

The level of resistance (RI) indicated by the MR/S ratios. Each value represents the mean $( \pm \mathrm{SE})$ of two experiments, each containing three replicates

${ }^{\mathrm{a}} \mathrm{GR}_{50}$, herbicide rate causing $50 \%$ growth reduction of plants

$\mathrm{b}_{50}$, herbicide concentration causing $50 \%$ inhibition of the ALS activity

${ }^{\mathrm{C}} \mathrm{RI}$ (resistance index) $=\mathrm{GR}_{50}$ or $\mathrm{I}_{50}(\mathrm{MR}) / \mathrm{GR} \mathrm{R}_{50}$ or $\mathrm{I}_{50}(\mathrm{~S})$

one of the seven databases, and 2276 (2.25\%) unigenes were annotated in all seven databases. The greatest sequence similarity was obtained with the Non-redundant database. The annotation results indicate that $M$. aquaticum was most similar to Beta vulgaris subsp. vulgaris (30.12\% of total unigenes) and Spinacia oleracea (15.08\%) (Additional files 3, 4).

GO and KEGG pathway analyses were performed to predict the functions of annotated unigenes and gene products. In total, 32,395 (31.98\%) unigenes were annotated with the GO database, and these were divided into 62 functional subgroups, including 23 for "biological process" (BP), 19 for "cellular component" (CC), and 20 for "molecular function" (MF) (Fig. 3). The largest gene subgroup in BP was cellular process (19,870 unigenes, $61.34 \%$ ), followed by metabolic process (17,951 unigenes, $55.41 \%)$ and single-organism process (15,128 unigenes, $46.70 \%)$. In the CC category, cell part (24,626 unigenes, $76.02 \%)$, organelle (13,079 unigenes, $40.37 \%)$, and organelle part $(10,216$ unigenes, $31.54 \%)$ were the most highly represented. The largest gene subgroup in MF was binding (19,390 unigenes, 59.85\%), followed by catalytic (16,550 unigenes, 51.09\%) and transporter (2461 unigenes,

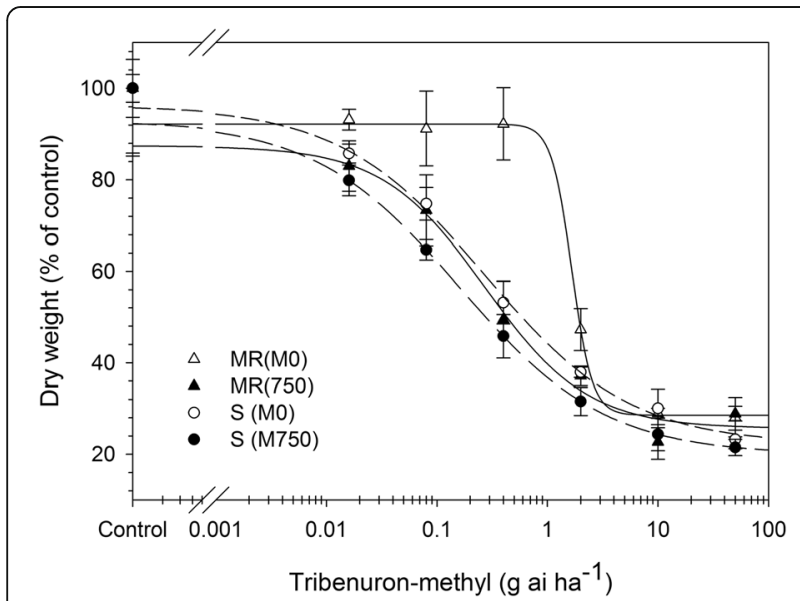

Fig. 1 Dose-response curves of susceptible (S) and resistant (MR) Myosoton aquaticum. Populations to tribenuron-methyl in the absence (M0) and presence of $750 \mathrm{~g}$ ai ha ${ }^{-1}$ malathion(M750). The solid lines for MR population, and the dash lines for $\mathrm{S}$ population. Each data point is the mean \pm SE of two experiments
7.60\%). Additionally, 16,475 unigenes were classified into 31 KEGG pathways comprising five terms, including cellular processes (5664 unigenes, 34.38\%), environmental information processing (7998 unigenes, 48.49\%), genetic information processing (4338 unigenes, 26.33\%), metabolism (10,079 unigenes, 61.18\%), and organismal systems (9979 unigenes, 60.57\%) (Fig. 4).

\section{Functional analysis of DEGs}

Transcript levels were calculated according to RPKM. In total, 4706 genes were differentially expressed between untreated MR(MR_C) and S (S_C) samples (|log2 (fold change) $\mid \geq 1$ and $q<0.05$ ), of which 1863 and 2843 were upregulated in MR_C and S_C, respectively. A comparison of TM-treated and untreated samples revealed 1146 and 3066 genes that were upregulated in MR and S, respectively. Meanwhile, 6296 genes were upregulated while 7245 were downregulated in MR_T as compared to in MR_C; and 5276 genes were upregulated while 4233 were downregulated in S_T as compared to S_C (Fig. 5A). Differential expression between MR and $\mathrm{S}$ in all four treatments was observed for 324 contigs (Fig. 5B), and 463 overlapping contigs were significantly upregulated in MR_T vs. S_T and in MR_C vs. S_C, including five annotated as CYP, two as

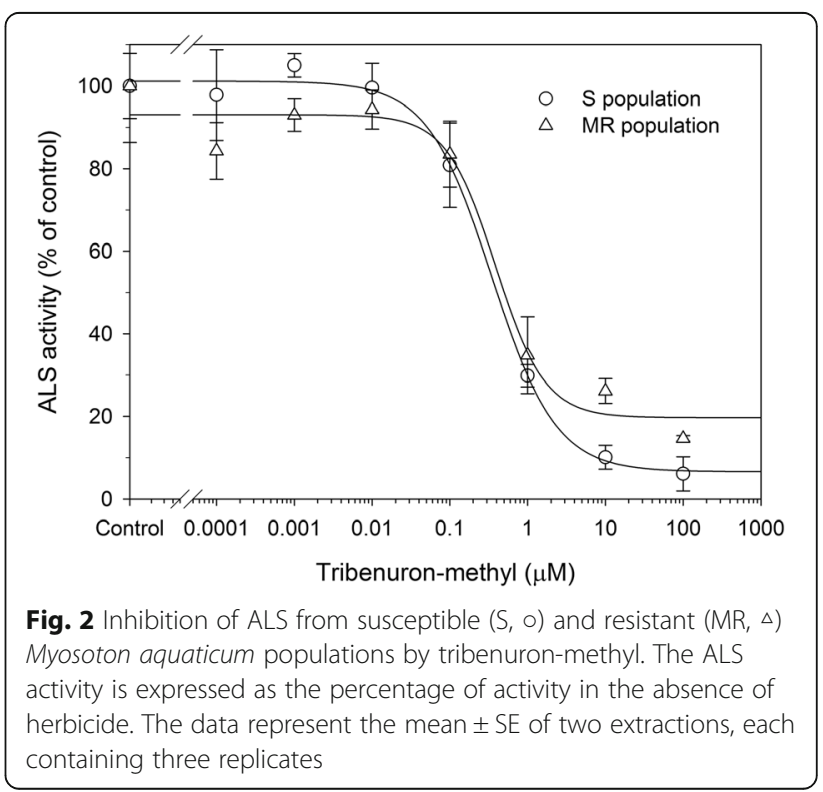


Table 2 Summary statistics of Myosoton aquaticum transcriptome sequencing and assembly

\begin{tabular}{ll}
\hline Total raw reads & $603,682,588$ \\
\hline Total clean reads & $551,895,330$ \\
Clean base & $82.78 \mathrm{G}$ \\
Total assembled transcripts & 182,036 \\
No.unigenes $>200 \mathrm{bp}$ & 101,307 \\
No.unigenes> $500 \mathrm{bp}$ & 44,649 \\
Maximum length & 102,348 \\
Minimum length & 201 \\
Average unigene length & 872 \\
N50 value & 1650 \\
N90 value & 324 \\
Total nucleotides of unigenes & $88,439,116$ \\
\hline
\end{tabular}

$\mathrm{ABC}$ transporters, one as GTs, three as POD, and two as esterases (Additional file 5).

To further characterize the function of the identified DEGs, we performed GO and KEGG pathway enrichment analyses. In total, 4212 genes that were differentially expressed between the MR_T and S_T samples were enriched in $53 \mathrm{GO}$ sub-terms (21 BP, $16 \mathrm{CC}$, and $16 \mathrm{MF})$. Among these DEGs, the GO sub-terms "cellular process" (1116, 26.50\%), "metabolic process" (1037, $24.62 \%)$, and "single-organism process" (792, 18.80\%) in the BP category; "cell part" (1415, 33.59\%), "organelle" (791, 18.78\%), and "membrane part" $(525,12.46 \%)$ in the CC category; and "binding" (1220, 28.96\%) and "catalytic" (1053, 25.00\%) in the MF category were enriched in MR relative to $\mathrm{S}$ samples. Moreover, the DEGs were enriched in 310 KEGG pathways, with the plant hormone signal transduction pathway enriched in MR and $\mathrm{S}$ populations. Among the genes that were differentially expressed between MR_T and S_T samples and were among the top 15 enriched pathways (Table 4), eight

Table 3 Sequence annotation of the Myosoton aquaticum transcriptome

\begin{tabular}{lll}
\hline Public database & $\begin{array}{l}\text { Number of } \\
\text { unigenes }\end{array}$ & Percentage (\%) \\
\hline Annotated in NR & 37,948 & 37.46 \\
Annotated in NT & 10,694 & 10.56 \\
Annotated in KEGG & 16,475 & 16.26 \\
Annotated in Uniprot & 33,717 & 33.28 \\
Annotated in PFAM & 24,049 & 23.74 \\
Annotated in GO & 32,395 & 31.98 \\
Annotated in COG & 13,379 & 13.21 \\
Annotated in all Databases & 2276 & 2.25 \\
Annotated in at least one Database & 44,117 & 43.55 \\
Total unigenes & 101,307 & 100 \\
\hline
\end{tabular}

and nine upregulated genes were enriched in the "metabolism of xenobiotics by CytP450" and "drug-metabolizing cytochrome CytP450" pathways, respectively. This indicates that CYP genes play an important role in metabolic resistance to TM in $M$. aquaticum.

\section{Selection of candidate metabolic resistance genes}

Based on the known mechanisms of metabolic resistance in weeds $[1,3,8,10]$, we speculated that DEGs related to metabolism and signaling pathways were more likely to be associated with metabolic resistance to TM. In the present study, we selected the overlapping genes that were upregulated in MRT_ST vs. MRC_SC (|log2(fold change) $\mid>1$ ) had related functional annotations, including those encoding CYPs, GSTs, GTs, and ABC transporters (Table 5). In addition, contigs with predicted annotations related to oxidase, POD, esterase, and hydrolase in the above-mentioned comparison or an assigned $\mathrm{GO}$ function related to pesticide metabolism were also selected (Van Eerd et al., 2003). In total of 34 contigs were selected (Table 5) for validating by qRT-PCR. Among these contigs, eight were annotated to the CYP family, one to the GST family, two to the GT family, two to the uridine diphosphate glucuronosyltransferase family, eight to the $\mathrm{ABC}$ transporter family, four to the POD family, and 9 to other families. The low number of candidate GST contigs is supported by the lack of difference in GST activity between MR and S plants (unpublished data).

\section{qRT-PCR validation of candidate metabolic resistance gene expression}

The expression of 34 candidate contigs was validated by qRT-PCR using original RNA samples from MR_T and S_T. We found that 10 of the contigs had higher expression levels in MR as compared to $\mathrm{S}$ samples (Table 5), including four for $\mathrm{CYP}$, four for the $\mathrm{ABC}$ transporter, and two for POD.

We further examined the expression levels of the 10 candidate contigs in additional plants and found that four of these were more highly expressed in MR than in $S$ plants (Table 5 and Fig. 6). Although there was some variation among individual plants, our analysis of the average expression levels of candidate contigs based on two rounds of qRT-PCR and RNA-Seq profiling revealed that three CYP and one $\mathrm{ABC}$ transporter were consistently and significantly overexpressed in MR (Fig. 6), including c28525_g1, c49866_g6, and c48448_g1 with homology to CYP734A1, CYP76C1, and CYP86B1, respectively, and c50054_g1 annotated as ABCC10.

\section{Discussion}

In the present study, we identified an $M$. aquaticum population (MR) that had evolved moderate (6.15-fold) 


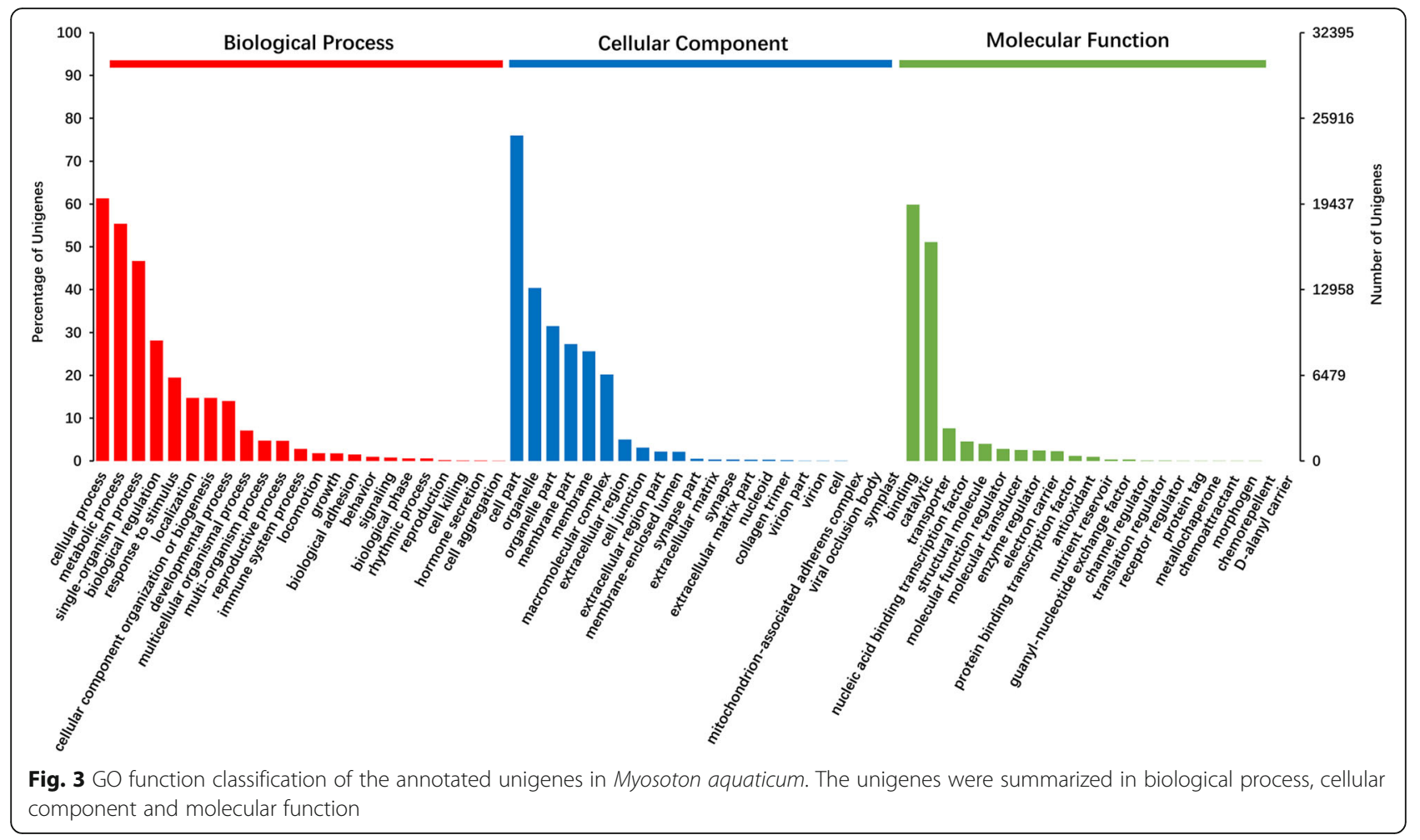

resistance to TM. We conclude that TM resistance in this population is due to CYP-mediated enhancement of herbicide metabolism rather than TSR based on the following lines of evidence: (1) ALS enzymes from S and MR plants exhibited similar in vitro sensitivity to TM; (2) ALS gene sequencing revealed no known ALS resistance mutations in resistant plants; and (3) treatment with the CYP inhibitor malathion reversed TM resistance. Malathion is known to inhibit the metabolism of sulfonylurea herbicides and thereby reverse metabolic resistance [7, 8]. Recent studies have indicated that metabolic resistance to ALS inhibitors is increasing among both monocot and dicot weed species, with co-occurrence of TSR frequently observed [1, 10, 3235]. There have been few studies on metabolism-based herbicide resistance without TSR in broadleaf weed species. M. aquaticum is a broadleaf weed that is widespread in China, with many populations exhibiting resistance to the ALS inhibitors including TM. Identifying genes involved in NTSR can provide insight into the evolution of metabolic resistance in dicot weeds as well as a basis for the development of strategies to overcome this resistance.

The present study provides a transcriptomic resource for future studies. Given that NTSR mechanisms differ among and within weed species [3], we performed two RNA-Seq analyses: once for de novo assembly of the $M$. aquaticum transcriptome, and another to identify candidate contigs associated with TM in a specific MR population. The 101,307 assembled unigenes had an average size of $872 \mathrm{bp}$; this number of unigenes is higher and their average size is similar than those reported for other weed species [14, 18, 23-26, 36-41].

Genes that were differentially expressed between untreated resistant and susceptible plants were more revealing than those detected after herbicide treatment. However, some studies have shown that upregulation of gene expression induced by ALS inhibitors is an important resistance mechanism [3, 21, 23]. A commercial formulation of TM was used in the present study because any allele(s) enabling individual plant survival to herbicide must be strongly selected by repeated application of both the herbicide and associated formulations under realistic field conditions [3]. Taking into consideration differences in genetic background and herbicide application in the two populations from different locations, we selected constitutive as well as herbicide-induced genes related to herbicide metabolism that were differentially expressed between $\mathrm{MR}$ and $\mathrm{S}$ biotypes as candidate genes involved in TM resistance in M. aquaticum.

In total, 10 contigs were selected as candidate NTSR genes (Table 5) presumed to encode proteins with homology to four CYPs (CYP734A1, CYP76C1, CYP86B1, and CYP94A1), four $\mathrm{ABC}$ transporters (ABCB2, $\mathrm{ABCC10,}$ $\mathrm{ABCC} 3$, and $\mathrm{ABCC} 10$ ), and two PODs (POD57). The qRT-PCR analysis confirmed that four of the contigs (c28525_g1 [CYP734A1], c49866_g6 [CYP76C1], c48448_g1 [CYP86B1], and c50054_g1 [ABCC10]) were expressed at 


\section{KEGG Functional Classification}

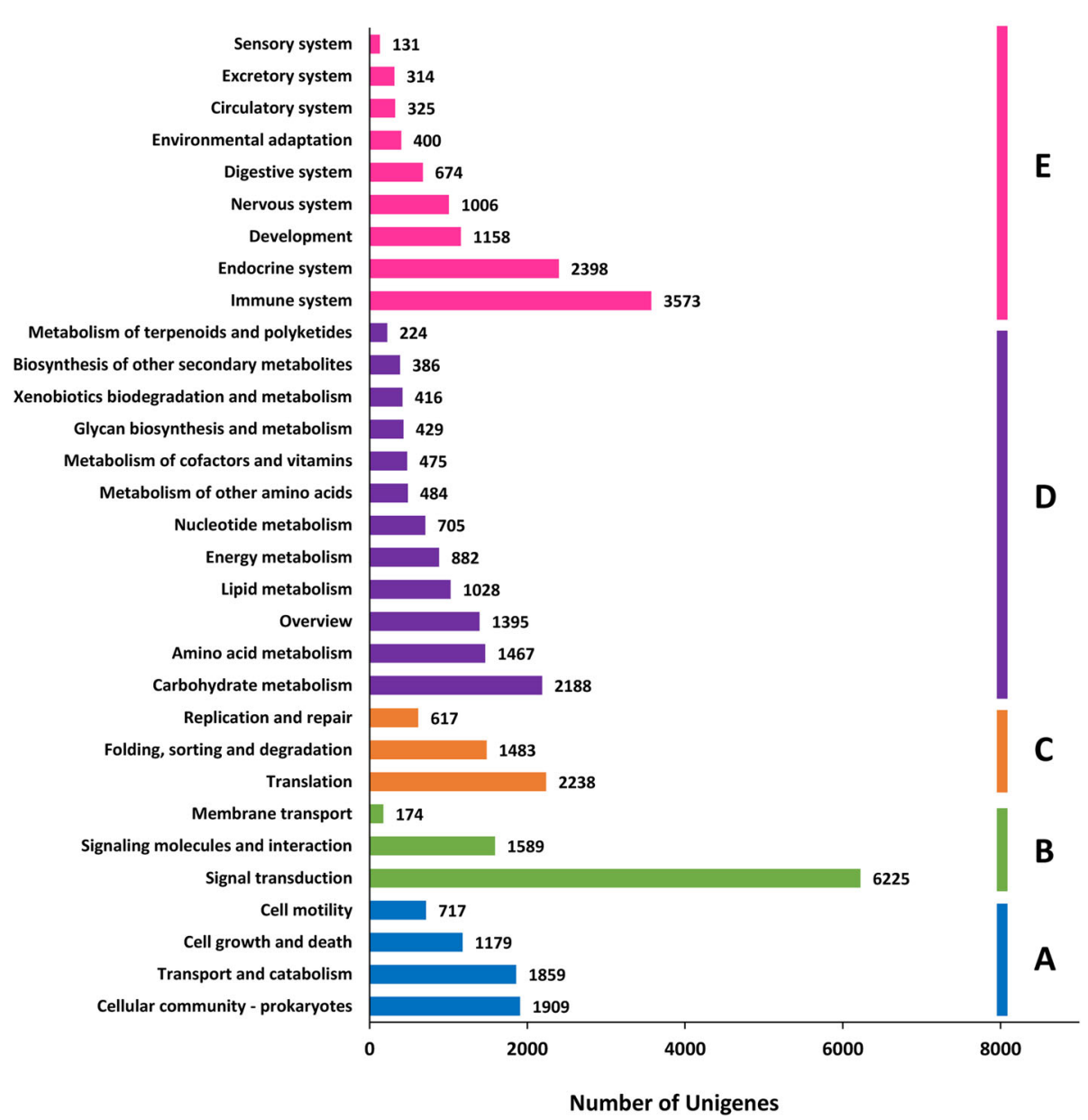

Fig. 4 KEGG function classification results of the annotated unigenes in Myosoton aquaticum. The $y$-axis lists the KEGG pathways. The x-axis indicates the number of genes. According to participation in KEGG pathways, unigenes were divided into five groups: A, cellular processes; B, environmental information processing; C, genetic information processing; D, metabolism; $E$, organism systems

consistently higher levels in MR than in S plants (Table 5 and Fig. 6). Variable expression of validated NTSR-related genes has also been reported in L. rigidum [19, 20], Echinochloa phyllopogon [42], D. sophia [26], A. aequalis [23], and many other weed species. NTSR in individual plants may arise from slightly different sets of resistance genes [26]. In our study, CYP734A1, CYP76C1, CYP86B1, and ABCC10 were identified as the major candidate genes conferring metabolic resistance to $M$. aquaticum.

CYPs play a critical role in the metabolism of secondary metabolites and catalyze diverse reactions in plants [43]. CYP-mediated herbicide metabolism has been well-characterized in resistant L. rigidum and E. phyllopogon, and several CYP isoforms were shown to confer metabolic resistance to ALS inhibitors and other herbicides via different modes of action $[8,10]$. CYP81A12 and CYP81A21 in E. phyllopogon metabolize penoxsulam and bensulfuron-methyl [42]; CYP72A31 in A. thaliana metabolizes bispyribac sodium and bensulfuron-methyl [44]; and CYP94A1 in common vetch (Vicia sativa L.) contributes to plant defense against chemical injury [45]. Transgenic $A$. thaliana expressing CYP76B1 and CYP76C subfamily members show enhanced resistance to monoterpenols and phenylurea herbicides [46]. The CYP734A family in plants typically functions in the catabolism of brassinosteroids, which protect against herbicide toxicity $[47,48]$. The CYP86A and CYP86B subfamilies catalyze hydroxylation of fatty acids (Compagnon et al. 2009; Pinot and Beisson 2011); CYP-mediated hydroxylation and epoxidation are also important pathways for herbicide degradation in plants (Siminszky 2006; Werck-Reichhart et al. 2000). In addition, CYP71AK2, CYP71A4, CYP72A254, CYP734A6, CYP86B1, CYP94A1, CYP94A2, CYP96A13, and CYP96A15 are highly expressed in ALS inhibitor-resistant E. phyllopogon [49], A. aequalis [23], D. sophia [26], and Echinochloa colona [50]. Moreover, CYPs 

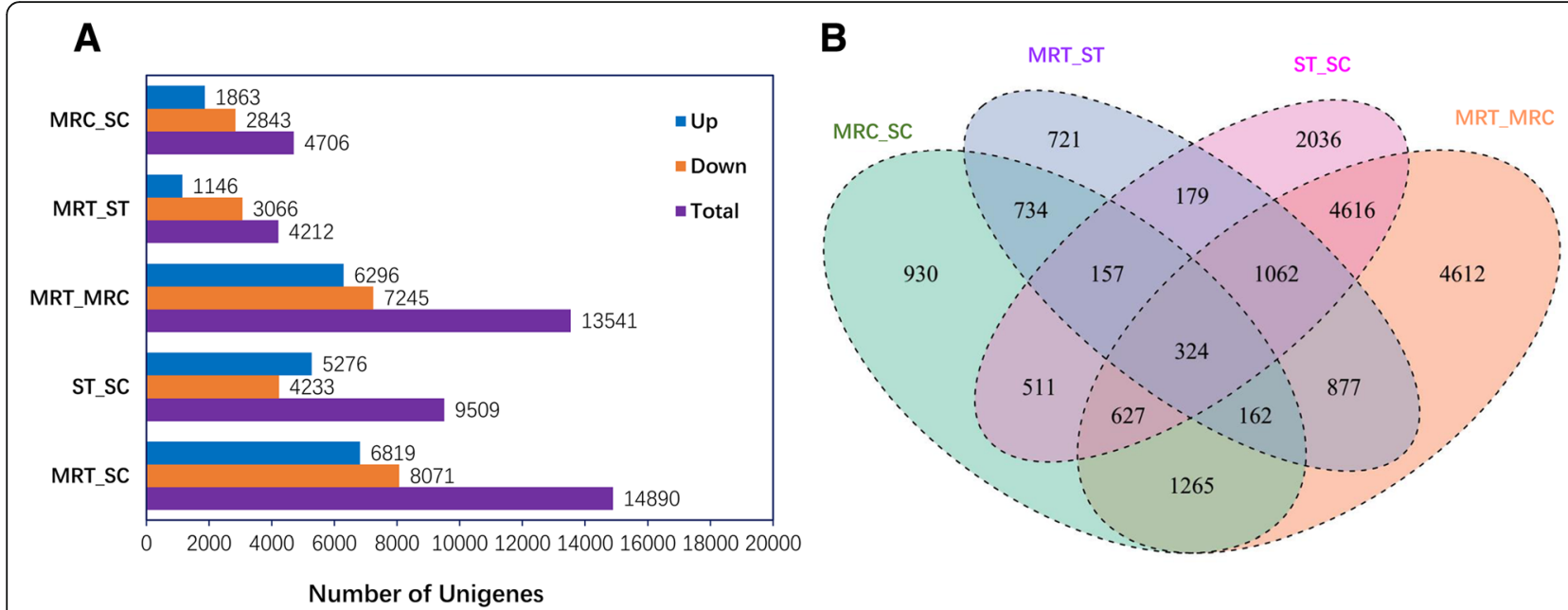

Fig. 5 The statistics of the DEGs between the Myosoton aquaticum treatment groups. (a) The number of DEGs between the different groups ${ }^{a}$. (b)

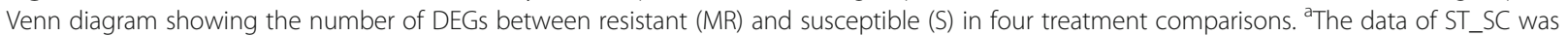
cited from another article. Bai S, Liu W, Wang H, Zhao N, Jia S, Zou N, Guo W, Wang J: Enhanced herbicide metabolism and metabolic resistance genes identified in tribenuron-methyl resistant Myosoton aquaticum L. J. Agric. Food Chem. 2018;66(37):9850-9857

associated with herbicide tolerance have been identified in crops such as CYP71C6v1 in wheat [51]; CYP81A6 and CYP72A31 in rice [44, 52]; CYP71A10 in soybean [53, 54]; CYP76B1in Jerusalem artichoke [55]; and CYP71A11 and CYP81B2 in tobacco [56]. Notably, a previous study reported that purified recombinant CYP71C6v1 expressed in wheat metabolized sulfonylurea herbicides, including bensulfuron-methyl, metsulfuron-methyl, chlorsulfuron, triasulfuron, and TM [51]. Thus, the CYP genes identified here in the MR population may play an important role in TM metabolism and resistance in M. aquaticum.

GST and GT are two other families of herbicide-detoxifying enzymes that contribute to NTSR [57-59]. GST and GT are associated with NTSR to ACCase and ALS inhibitors in the grass weeds L. rigidum and A. myosuroides [18-21]. In addition, the

Table 4 The fifteen enriched KEGG pathway terms of the DEGs between tribenuron-methyl treated MR and S Myosoton aquaticum populations

\begin{tabular}{|c|c|c|c|c|c|}
\hline \multirow[t]{2}{*}{ KEGG pathway term } & \multirow[t]{2}{*}{ Map ID } & \multicolumn{2}{|c|}{ Gene Count ${ }^{\mathrm{a}}$} & \multirow{2}{*}{$\begin{array}{l}\text { Genes } \\
\text { in back } \\
\text { ground }^{b}\end{array}$} & \multirow[t]{2}{*}{$P$-Value } \\
\hline & & Up & Down & & \\
\hline Biosynthesis of secondary metabolites & map01110 & 94 & 228 & 1505 & $5.94 \mathrm{E}-09$ \\
\hline Plant-pathogen interaction & map04626 & 64 & 21 & 258 & $1.51 \mathrm{E}-11$ \\
\hline Ribosome biogenesis in eukaryotes & map03008 & 61 & 12 & 217 & 1.44E-10 \\
\hline Plant hormone signal transduction & map04075 & 36 & 48 & 233 & 7.67E-14 \\
\hline Phenylpropanoid biosynthesis & map00940 & 26 & 40 & 163 & 7.23E-14 \\
\hline Phenylalanine metabolism & map00360 & 22 & 29 & 161 & 7.15E-07 \\
\hline Starch and sucrose metabolism & map00500 & 18 & 60 & 277 & $2.58 \mathrm{E}-07$ \\
\hline Valine, leucine and isoleucine biosynthesis & map00290 & 10 & 3 & 37 & $3.89 \mathrm{E}-03$ \\
\hline Drug metabolism - cytochrome P450 & map00982 & 9 & 10 & 66 & 7.02E-03 \\
\hline Metabolism of xenobiotics by cytochrome P450 & map00980 & 8 & 11 & 72 & 1.83E-02 \\
\hline Nicotinate and nicotinamide metabolism & map00760 & 8 & 4 & 40 & $2.10 \mathrm{E}-02$ \\
\hline Chemical carcinogenesis & map05204 & 8 & 10 & 74 & 4.56E-02 \\
\hline Pentose and glucuronate interconversion & map00040 & 6 & 27 & 122 & $1.52 \mathrm{E}-03$ \\
\hline Limonene and pinene degradation & map00903 & 6 & 5 & 33 & 1.19E-02 \\
\hline alpha-Linolenic acid metabolism & map00592 & 5 & 10 & 45 & 3.57E-03 \\
\hline
\end{tabular}

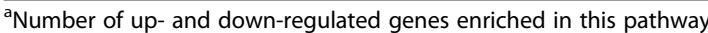

${ }^{\mathrm{b}}$ Number of unigenes annotated in this pathway 
Table 5 Identification of the up-regulated unigenes annotated and related to metabolic resistance in Myosoton aquaticum by RNASeq and qRT-PCR $\left(2^{-\Delta C t}\right)$

\begin{tabular}{|c|c|c|c|c|c|c|}
\hline \multirow[t]{2}{*}{ Gene ID } & \multirow[t]{2}{*}{ PFAM ID } & \multirow[t]{2}{*}{ Function annotation } & \multicolumn{2}{|l|}{ RNA-Seq } & \multicolumn{2}{|c|}{ FoldChage: qRT-PCR $\left(2^{-\Delta C t}\right)$} \\
\hline & & & Padj $^{a}$ & FoldChange (MRT_ST) & $P$-value ${ }^{b}$ & RNA-Seq samples (MRT_ST) \\
\hline c47752_g3 & PF00067.17 & CytP450, CYP716B1 & $2.40 \mathrm{E}-02$ & 2.41 & $1.81 \mathrm{E}-01$ & $1.24(0.17)$ \\
\hline c49980_g3 & PF00067.17 & CytP450, CYP71A21 & 2.37E-02 & 3.24 & $6.00 \mathrm{E}-03$ & $0.56(0.14)$ \\
\hline c31888_g1 & PF00067.17 & CytP450, CYP72A219 & 7.73E-05 & 2.16 & $1.00 \mathrm{E}-03$ & $0.45(0.08)$ \\
\hline c28525_g1 & PF00067.17 & CytP450, CYP734A1 & $6.32 \mathrm{E}-07$ & 2.28 & 5.00E-03 & $1.94(0.2) * *$ \\
\hline c49866_g6 & . & CytP450, CYP76C1 & $3.73 \mathrm{E}-02$ & 2.19 & 3.67E-04 & $3.22(0.34)^{* * *}$ \\
\hline c44104_g1 & PF00067.17 & CytP450, CYP82A4 & $2.69 \mathrm{E}-02$ & 3.4 & 7.10E-02 & $0.91(0.06)$ \\
\hline c48448_g1 & PF00067.17 & CytP450, CYP86B1 & 4.16E-06 & 2.04 & $1.00 \mathrm{E}-03$ & $1.27(0.03)^{* *}$ \\
\hline c14606_g1 & PF00067.17 & CytP450, CYP94A1 & 2.67E-01 & 1.49 & $1.31 \mathrm{E}-01$ & $1.46(0.25)$ \\
\hline c50084_g2 & PF00032.12 & Cytochrome b6-f & $1.68 \mathrm{E}-02$ & 5.22 & 4.30E-02 & $0.85(0.08)$ \\
\hline c49404_g2 & PF01578.15 & Cytochrome c & $2.56 \mathrm{E}-02$ & 5.17 & $9.04 \mathrm{E}-01$ & $1.02(0.17)$ \\
\hline c48737_g9 & . & Cytochrome c1-2 & $1.72 \mathrm{E}-02$ & 2.47 & 4.30E-02 & $0.54(0.12)$ \\
\hline c27216_g1 & PF13417.1 & GST, T1 & $8.89 \mathrm{E}-01$ & 1.09 & 4.40E-01 & $0.89(0.18)$ \\
\hline c33248_g1 & PF03552.9 & Glycosyltransferase, GT28 & $1.94 \mathrm{E}-04$ & 2.79 & $1.00 \mathrm{E}-03$ & $0.13(0.01)$ \\
\hline c33752_g1 & PF00295.12 & Glycosyltransferase, GT28 & 3.39E-02 & 3.26 & $3.00 \mathrm{E}-03$ & $0.27(0.06)$ \\
\hline c47986_g3 & PF00201.13 & UDP-glycosyltransferase, UGT73B3 & 4.04E-07 & 3.48 & $3.16 \mathrm{E}-01$ & $0.89(0.13)$ \\
\hline c32196_g1 & PF00201.13 & UDP-glycosyltransferase, UGT78D2 & $8.88 \mathrm{E}-01$ & 1.07 & $1.30 \mathrm{E}-01$ & $1.28(0.25)$ \\
\hline c40202_g1 & PF04577.9 & Glucosamine transferase & $6.23 \mathrm{E}-03$ & 2.37 & $6.24 \mathrm{E}-01$ & $0.95(0.16)$ \\
\hline c30791_g1 & . & $\mathrm{ABC}$ transporter, $\mathrm{ABCB} 2$ & 1.34E-04 & 2.15 & $2.00 \mathrm{E}-03$ & $0.65(0.05)$ \\
\hline c49741_g6 & & $\mathrm{ABC}$ transporter, $\mathrm{ABCB} 2$ & $6.75 \mathrm{E}-13$ & 2.62 & $1.00 \mathrm{E}-03$ & $2.29(0.2) * *$ \\
\hline c49337_g1 & PF03468.9 & $\mathrm{ABC}$ transporter, $\mathrm{ABCB} 29$ & $6.96 \mathrm{E}-04$ & 2.8 & $9.20 \mathrm{E}-02$ & $0.7(0.06)$ \\
\hline c45895_g2 & & $\mathrm{ABC}$ transporter, $\mathrm{ABCC} 10$ & $1.05 \mathrm{E}-03$ & 2.45 & $2.00 \mathrm{E}-03$ & $1.96(0.2)^{* *}$ \\
\hline c45895_g3 & . & $\mathrm{ABC}$ transporter, $\mathrm{ABCC} 10$ & $5.12 \mathrm{E}-07$ & 4.89 & $9.20 \mathrm{E}-02$ & $0.76(0.04)$ \\
\hline c50054_g1 & PF00005.22 & $\mathrm{ABC}$ transporter, $\mathrm{ABCC} 10$ & $9.18 \mathrm{E}-06$ & 2.61 & $2.10 \mathrm{E}-02$ & $2.16(0.53) *$ \\
\hline c39205_g1 & PF00664.18 & $\mathrm{ABC}$ transporter, $\mathrm{ABCC} 3$ & $4.55 \mathrm{E}-11$ & 2.16 & 7.50E-02 & $1.54(0.33) * *$ \\
\hline c47115_g3 & PF00664.18 & $\mathrm{ABC}$ transporter, $\mathrm{ABCC} 8$ & 2.97E-02 & 2.67 & 6.30E-02 & $0.67(0.04)$ \\
\hline c37150_g1 & PF00403.21 & Peroxidase & 5.01E-06 & 2.51 & 7.00E-03 & $0.59(0.13)$ \\
\hline c44363_g1 & PF00141.18 & Peroxidase 5 & $7.23 \mathrm{E}-25$ & 6.74 & $1.56 \mathrm{E}-04$ & $0.38(0.07)$ \\
\hline c33094_g1 & PF00141.18 & Peroxidase 57 & $3.49 \mathrm{E}-14$ & 3.94 & $1.30 \mathrm{E}-02$ & $1.93(0.34) *$ \\
\hline c42442_g1 & PF00141.18 & Peroxidase 57 & $1.15 \mathrm{E}-06$ & 1.79 & $2.39 \mathrm{E}-04$ & $1.73(0.07) * * *$ \\
\hline c44336_g7 & 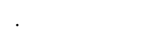 & Oxidase & $2.75 \mathrm{E}-02$ & 4.2 & $1.00 \mathrm{E}-03$ & $0.54(0.02)$ \\
\hline c40277_g1 & PF00657.17 & Esterase & $6.59 \mathrm{E}-23$ & 3.88 & $2.00 \mathrm{E}-03$ & $0.44(0.05)$ \\
\hline c48393_g3 & . & Esterase & $2.56 \mathrm{E}-04$ & 3.7 & 3.81E-01 & $0.85(0.22)$ \\
\hline c35829_g1 & PF00722.16 & Hydrolase & $1.24 \mathrm{E}-04$ & 4.59 & 8.90E-02 & $0.82(0.11)$ \\
\hline c50023_g1 & PF10551.4 & Hydrolase & $2.51 \mathrm{E}-08$ & 4.73 & $6.00 \mathrm{E}-02$ & $1.12(0.05)$ \\
\hline
\end{tabular}

MR_T, resistant $M$. aquaticum L seedlings sprayed tribenuron-methyl; S_T, susceptible $M$. aquaticum $L$ seedlings sprayed tribenuron-methyl ${ }^{a}$ The resulting $p$-value was adjusted and expressed as the padj by the Benjamini-Hochberg procedure for controlling the false discovery rate ${ }^{\mathrm{b}}$ Means were separated using Fisher's protected least significant difference (LSD) test at the $5 \%$ level of probability (from SPSS analysis)

${ }^{c} P$-value of $<0.05,0.01,0.001$ is indicated by ${ }^{*}, * *$, and ${ }^{* * *}$, respectively (from SPSS analysis)

overexpression of two GST genes (GST-T3 and -F1) and two GT genes (GT83A1 and GT75D1) has been linked to the mesosulfuron-methyl resistance in the grass weed A. aequalis [23]. In the present study, one GST and five GT contigs were annotated; however, the expression of the corresponding genes did not differ significantly between MR and S plants (Table 5), suggesting that they do not contribute to TM resistance in M. aquaticum. The lack of involvement of GST and GT in ALS inhibitor resistance in dicot weeds has also been documented in TM-resistant $D$. sophia, and may be attributable to (1) distinct ALS herbicide resistance genes in grass and 


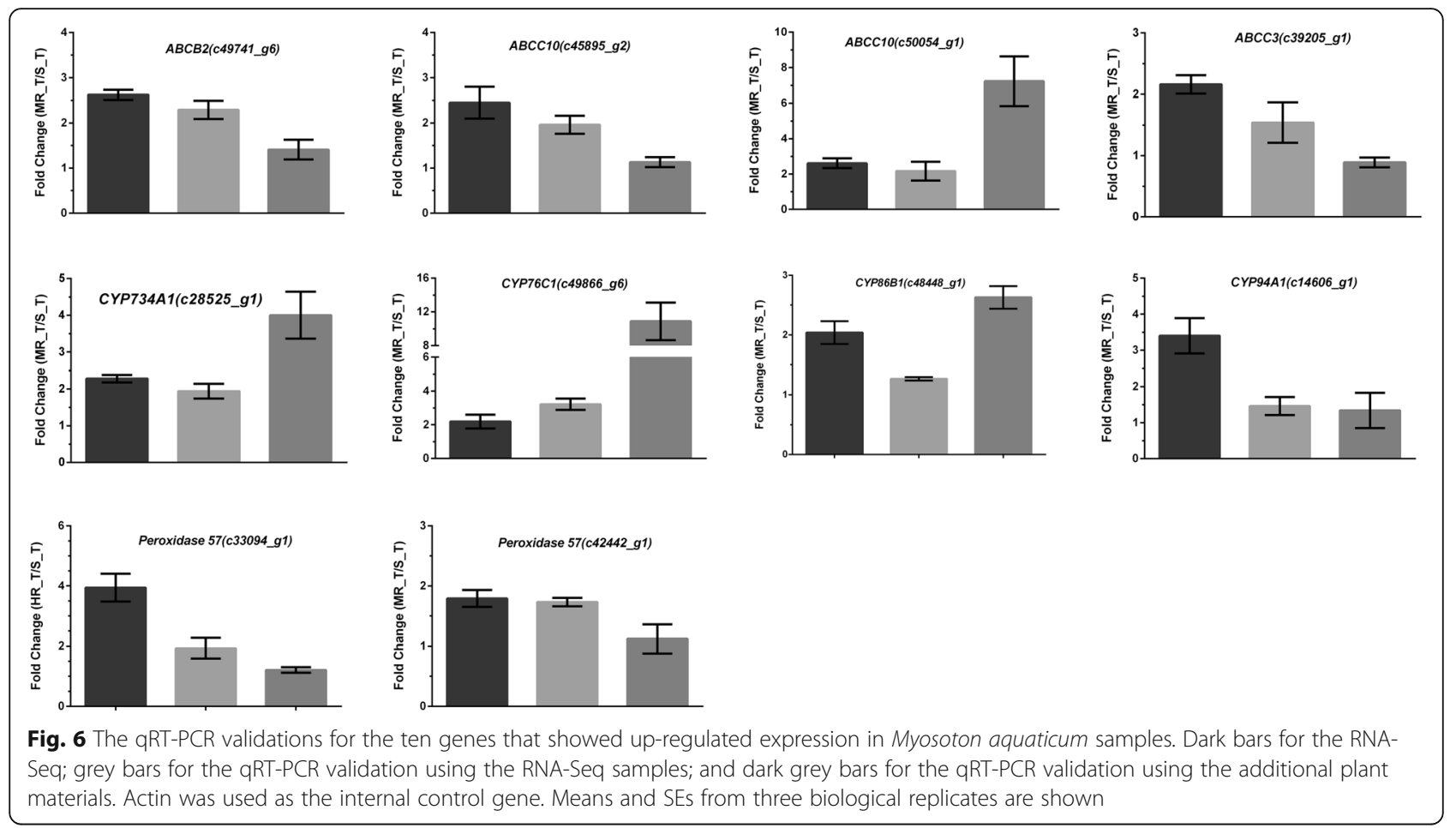

broadleaf species; (2) differences in the metabolism of specific ALS herbicides; (3) variable recombination resulting from self- and cross-pollination; and (4) insufficient data.

Plant $\mathrm{ABC}$ transporter families are among the largest and most diverse, and have been implicated in the detoxification of xenobiotics, including herbicides $[60,61]$. However, in contrast to CYP, GST, and GT gene families that are involved in metabolic resistance to herbicides, $A B C$ transporters function by compartmentalizing herbicides and/or their metabolites [43]. In the present study, one contig (c50054_g1) was annotated to $A B C C 10$ and may be associated with TM resistance. Similar results were recently reported in several weed species: $A B C C 1$ in a resistant $D$. sophia population was implicated in TM resistance [26]; $A B C C 8$ and $A B C B 11$ were linked to metabolic resistance to mesosulfuron-methyl in multi-herbicide-resistant $A$. aequalis [23]; $A B C B 10$ was upregulated in a resistant $B$. syzigachne population exhibiting NTSR to fenoxaprop-P-ethyl $[22,23]$; and several $A B C$ transporters were highly expressed in glyphosate-resistant horseweed (Conyza canadensis) [62, 63] and Lolium perenne [25], as well as in paraquat-resistant goosegrass (Eleusine indica L.) [14]. In fact, $\mathrm{ABC}$ transporter activity towards herbicide metabolites is well established in plants and protects against toxicant injury. The $\mathrm{ABC}$ transporter AtABCC1/AtMRP1 exhibits enzymatic activity towards the GS-conjugated herbicide metolachlor, whereas AtABCC1 and AtABCC2 in A. thaliana mediate tolerance to arsenic and arsenic-based herbicides [64]. The ABC transporter AtOPT6 in A. thaliana is associated with resistance to the herbicide primisulfuron [65]. In addition, overexpression of AtPgp1-a multi-drug resistance gene family member-and its garden pea homo$\log$ psNTP9 have been shown to confer resistance to multiple herbicides in A. thaliana [66]. It is thus likely that $A B C C 10$ contributes to metabolic resistance to TM in $M$. aquaticum.

Peroxidase, oxidase, esterase, and hydrolase families are implicated in NTSR [1]. In the present study, we identified nine upregulated contigs potentially encoding proteins with homology to these enzymes; however, their expression levels did not differ significantly between MR and $S$ plants in validation experiments (Table 5). Similar to these results, a previous study reported that POD is unlikely to be involved in TM resistance in the broadleaf weed D. sophia [26]. We propose that POD, oxidase, esterase, and hydrolase genes are unlikely to be associated with TM resistance in M. aquaticum.

\section{Conclusion}

An $M$. aquaticum population (MR) moderately resistant to TM was identified in this study, and was found to exhibit NTSR rather than TSR, which is likely due to CYP-mediated metabolic resistance and $\mathrm{ABC}$ transporter-mediated sequestration of metabolites. The contigs c28525_g1 (with homology to CYP734A1), c49866 g6 (with homology to CYP76C1), c48448_g1 (with homology to CYP86B1), and c50054_g1 (with homology to $A B C C 10$ ) are potential NTSR genes or markers for metabolic resistance to TM in $M$. aquaticum. Other genes potentially involved in herbicide 
resistance may be discovered by analyzing other resistant $M$. aquaticum populations. The functional characterization of these genes using yeast and $A$. thaliana transgenic systems is now underway; future studies should investigate the regulation of metabolic resistance genes to elucidate the NTSR network in weeds. Our findings provide insight into the molecular basis of metabolic herbicide resistance mechanisms in broadleaf weed and a basis for developing weed management strategies to overcome this major threat to crop production.

\section{Methods}

\section{Plant materials}

Mature seeds of resistant $M$. aquaticum $\mathrm{HN} 10$ were harvested from winter wheat fields in Zhumadian, Henan Province $\left(32^{\circ} 58^{\prime} 16^{\prime \prime} \mathrm{N}\right.$, E $\left.114^{\circ} 38^{\prime} 54^{\prime \prime}\right)$, in 2013. Seeds collected from at least 30 mature plants randomly distributed in the field were thoroughly mixed, air dried, and stored in paper bags at $4{ }^{\circ} \mathrm{C}$ until use. A previously documented herbicide-susceptible population (HN03, designated S) originating from Xixian, Henan Province $\left(32^{\circ} 19^{\prime} 08.16^{\prime \prime} \mathrm{N}, 114^{\circ} 45^{\prime} 09.62^{\prime \prime} \mathrm{E}\right)$, served as the control in the present study [28].

Prior to planting, seeds were germinated on $0.6 \%(w / v)$ plant agar in an artificial chamber $\left(20{ }^{\circ} \mathrm{C} / 15{ }^{\circ} \mathrm{C}, 12: 12\right.$-h light/dark cycle), and seedlings were transplanted into plastic pots (20 per pot) filled with potting mix (50\% organic matter and moist loam soil, pH 5.6). The pots were randomly distributed in a greenhouse under controlled conditions (natural sunlight, $25{ }^{\circ} \mathrm{C} / 15{ }^{\circ} \mathrm{C}, \sim 75 \%$ relative humidity), with no fertilizer supplementation and watering every $48 \mathrm{~h}$. The seedlings were thinned to 10 uniform plants per pot at the 2-3 leaf stage, were treated with herbicides when they reached the 3-4 leaf stage. The herbicides were sprayed using a compressed-air moving-nozzle cabinet sprayer equipped with a TeeJet 9503EVS flat fan nozzle and calibrated to deliver $450 \mathrm{~L} \mathrm{ha}^{-1}$ at $275 \mathrm{kPa}$. After the treatment, the plants were returned to the greenhouse and the number of survivors (plants with no new growth were considered as dead) or biomass (dry weight of above-ground material) was recorded 3 weeks after herbicide treatment.

Twice-selected resistant plants derived from HN10 were used for experiments. Briefly, a single-rate screen test was performed to identify resistant plants as described in our previous study [27]. Plants that survived treatment with $22.5 \mathrm{~g}$ ai ha ${ }^{-1}$ (2-fold higher than the field recommend rate) TM (75\% WG; DuPont, Juxing, Shanghai, China) were selected for $A L S$ gene sequencing. Resistant plants with no known ALS resistance mutations were isolated before flowering and F1 seeds were obtained by cross pollination. The seeds were germinated and cultivated for a second round of TM resistance selection, and $A L S$ sequencing was performed as described above to obtain F2 seeds (designated MR).

\section{Effect of malathion on TM resistance}

Whole-plant response experiments were carried out to determine the sensitivity of $S$ and MR populations to $\mathrm{TM}$ in the absence and presence of malathion as described in our previous study [29]. The malathion application rate was $750 \mathrm{~g}^{\mathrm{ai} \mathrm{ha}}{ }^{-1}$, and there was no negative effect on $M$. aquaticum seedling growth. TM was applied at $0,0.016,0.08,0.4,2.0,10$, and $50 \mathrm{~g}$ ai ha ${ }^{-1}$ to $\mathrm{S}$ and MR populations. The above-ground material was harvested 21 days after herbicide treatment and the dry weight was recorded. There were three replicates per treatment, and the experiment was performed twice.

\section{In vitro ALS inhibition assay}

Seedlings from the $\mathrm{S}$ and MR populations were harvested at the 3-4 leaf stage. ALS extraction and the in vitro herbicide inhibition assay were performed as previously described $[67,68]$. ALS activity was determined colorimetrically $(530 \mathrm{~nm})$ with a ultraviolet spectrophotometer (Thermo Fisher Scientific, Waltham, MA, USA) by measuring acetoin production. Three subsamples from each extraction were assayed, with two extractions per population.

\section{Statistical analysis}

Values from repeated experiments were subjected to one-way analysis of variance $(P \leq 0.05)$; since there were no statistically significant differences between repeats, the data were pooled and subjected to non-linear regression analysis using SigmaPlot v.12.5 (Systat, San Jose, CA, USA). The herbicide rate or dose resulting in $50 \%$ growth reduction $\left(\mathrm{GR}_{50}\right)$ or $50 \%$ inhibition of ALS activity $\left(I_{50}\right)$ was estimated using a four-parameter log-logistic model:

$$
Y=C+\frac{D-C}{1+\left(x / E D_{50}\right)^{b}}
$$

where $C$ is the lower limit, $D$ is the upper limit, $b$ is the slope at $E D_{50}$, and $E D_{50}$ is the effective dose causing a $50 \%$ reduction. The resistance index was calculated by dividing the $\mathrm{GR}_{50}$ or $\mathrm{I}_{50}$ value of the resistant population by that of the sensitive population.

\section{ALS gene sequencing}

Genomic DNA was extracted from shoot tissue of individual plants at the 3- to 4-leaf stage using the Plant Genomic DNA kit (Tiangen Biotech, Beijing, China) according to the manufacturer's instructions. The primers used to amplify the $M$. aquaticum $A L S$ gene fragment containing five conserved regions (A to E) and PCR 
protocol have been described elsewhere [69, 70]. PCR products were purified with $1.0 \%$ agarose gels using the TIANgel Midi Purification kit (Tiangen Biotech) and were sequenced from both ends by Shanghai Sangon Biological Engineering and Technology Service Co. (Shanghai, China). Sequence data were aligned and compared using DNAMAN v.8.0.8 software (Lynnon Biosoft, San Ramon, CA, USA).

\section{Sample collection and preparation for RNA-Seq}

The confirmed resistant (MR) and susceptible (S) $M$. aquaticum populations were cultivated and treated with herbicide as described above and $24 \mathrm{~h}$ later, leaf materials were collected from treated MR and $S$ as well as untreated control plants. The experimental design included three biological replicates of MR and $S$ for the untreated control and TM (T; $11.25 \mathrm{~g}_{\text {ai }} \mathrm{ha}^{-1}$ ) treatments, for a total of twelve 10-seedling combinations of the MR and $\mathrm{S}$ populations. Collected samples (three biological replicates $\times$ two treatments $\times$ two populations) were immediately frozen in liquid nitrogen and stored at $-80{ }^{\circ} \mathrm{C}$ until RNA extraction.

\section{RNA extraction, library construction, sequencing, and bioinformatics analysis}

Total RNA extraction and quality control were performed according to standard protocols [23]. cDNA library construction and Illumina sequencing were performed by Annoroad Gene Technology Co. (Beijing, China); 150-bp paired-end reads were obtained using an HiSeq 4000 platform (Illumina, San Diego, CA, USA). Raw reads (transformed by the Consensus Assessment of Sequence and Variation (CASAVA, v.1.8.2)) containing the adapter poly-N (> 5\% of the unknown sequences designated as "N") and low-quality reads (> 15\% bases with quality value $<20$ ) were filtered out using in-house Perl scripts to obtain high-quality clean reads. De novo transcriptome assembly was conducted in Trinity v.20140717 [71] under its default parameter values, to obtain the transcripts and unigenes-the longest transcript of a set of transcripts that appears to originate from the same transcription locus. To evaluate the accuracy of assembly, all unigenes were matched to the sequences of Arabidopsis thaliana (L.) Heynh, using the BLAST-Like Alignment Tool (BLAST) with $\mathrm{E} \leq 1 \mathrm{e}-20$. The bioinformatics analysis strategy for obtained unigenes is detailed in our previous study [23]. Briefly, after de novo transcriptome assembly, the possible open reading frames for each unigene were identified with TransDecoder v.20140717 [72]. To obtain comprehensive, functional information regarding the sequences, unigenes were annotated using seven publicly available databases (Table 3) by means of local BLAST programs (NCBI, NIH, Bethesda, USA) which used a significance threshold of $\mathrm{E}<1 \mathrm{e}-5$. In addition, Trinotate v.20140717 software was used to identify protein domains, predict signal peptides, and locate transmembrane regions [7375]. Gene Ontology (GO, http://www.geneontology.org/) annotation of unigenes was performed with Blast2GO [76], and GO functional classification was carried out using WeGO software (http://wego.genomics.org.cn) [77]. Pathway assignment was performed using the Kyoto Encyclopedia of Genes and Genomes (KEGG) Automatic Annotation Server (http://www.genome.jp/ kegg/kaas/).

\section{Analysis of differentially expressed genes (DEGs)}

cDNA libraries were constructed for three biological replicates each of MR and S samples with TM treatment (referred to as MR_T and S_T, respectively) and six corresponding control samples (MR_C and S_C, respectively). Quality assessment and sequencing were carried out for the 12 samples as described above. Gene expression levels were calculated based on reads per kilobase million mapped reads (RPKM) [78]. Differences in the abundance of each read between sample pairs (MR_C vs. S_C, MR_T vs. S_T, MR_T vs. MR_C, S_T vs. S_C, and MR_T vs. S_C) were calculated using DESeq 2 v.1.4.5 [79]. The resultant $P$ values were converted to $q$ values using the Benjamini-Hochberg procedure to minimize the false discovery rate [80]. Genes with $\mathrm{q}<0.05$ and $\mid \log 2$ (fold change) $\mid \geq 1$ were identified as DEGs, and were further analyzed by GO and KEGG enrichment analysis with the hypergeometric test [81], in which the $P$ value was adjusted for multiple comparisons to a $q$ value and genes in the whole genome served as background data. GO or KEGG terms with $\mathrm{q}<0.05$ were considered as significantly enriched.

\section{Identification of candidate resistance genes and verification of relative expression levels}

To verify the reliability of expression data, 34 candidate resistance genes were selected and their levels were quantified by qRT-PCR using the primers listed in Additional file 6.

Total RNA was extracted and purified using the RNApre Pure Plant kit (Tiangen Biotech), and $1 \mu \mathrm{g}$ was used for first-stand cDNA synthesis with the FastQuant RT Super Mix Kit (Tiangen). qRT-PCR was performed in 96-well plates on a LightCycler 96 system (Roche, Basel, Switzerland) using SuperReal PreMix Plus (SYBR Green) (Tiangen). The $20 \mu \mathrm{L}$ reaction mixture contained $10 \mu \mathrm{L}$ of $2 \times$ SuperReal PreMix Plus, $1 \mu \mathrm{L}$ diluted cDNA, $0.6 \mu \mathrm{L}$ primers, and $7.8 \mu \mathrm{L}$ RNase-free $\mathrm{ddH}_{2} \mathrm{O}$, with three replicates prepared of each cDNA sample. The reaction conditions were as follows: $95{ }^{\circ} \mathrm{C}$ for $15 \mathrm{~min}$, followed by 40 cycles of $95{ }^{\circ} \mathrm{C}$ for $10 \mathrm{~s}, 60{ }^{\circ} \mathrm{C}$ for $20 \mathrm{~s}$, and $72{ }^{\circ} \mathrm{C}$ for $20 \mathrm{~s}$. At the end of the reaction, melting 
curve analysis was performed to confirm that there was no non-specific amplification; similar amplification efficiencies were observed for the target and internal control genes (90.0-103.7\%). Fold change in gene expression was calculated with the comparative cycle threshold (CT) method $\left(2^{-\Delta \mathrm{Ct}}\right)$ [82] relative to samples from susceptible plants, where $\Delta \mathrm{CT}=[\mathrm{CT}$ target gene $\mathrm{CT}$ actin]. Data were normalized against to the expression level of actin (GenBank accession no. KP099106.1), a housekeeping gene. Three biological replicates of each treatment were prepared. The qRT-PCR data were analyzed with the Student's $t$-test $(P<0.05)$ using SPSS software (SPSS Inc., Chicago, IL, USA).

The expression patterns of unigenes whose relative expression levels were verified by qRT-PCR were in accordance with RNA-Seq profiles were also confirmed in additional samples (seed germination, plant cultivation, herbicide treatment under the same conditions, and RNA extraction following RNA-Seq) collected at $72 \mathrm{~h}$ after TM treatment.

\section{Additional files}

Additional file 1: Quality assessment of the reads generated from RNASeq for the resistant (MR) and susceptible (S) Mysoton aquaticum populations. (XLSX $10 \mathrm{~kb}$ )

Additional file 2: Length distribution of unigenes characterized from the RNA-seq libraries of Myosoton aquaticum. (PDF $49 \mathrm{~kb}$ )

Additional file 3: Species distributions of the BLASTX matches of the Myosoton aquaticum transcriptome unigenes. (PDF $6 \mathrm{~kb}$ )

Additional file 4: The annotation for unigenes of Myosoton aquaticum. (XLSX $14194 \mathrm{~kb}$ )

Additional file 5: The respective numbers of overlapping up-regulated genes in comparative treatment groups. (XLSX $10 \mathrm{~kb}$ )

Additional file 6: Primer pairs used for the GRT-PCR relative quantification of gene expression in Myosoton aquaticum. (DOCX $19 \mathrm{~kb})$

\section{Abbreviations \\ ABC: ATP-binding cassette; ACCase: Acetyl-coenzyme A carboxylase; BLAST: Basic Local Alignment Search Tool; BP: Biological process; CASAVA: Consensus Assessment of Sequence and Variation; CC: Cellular component; CYP: Cytochrome P450 monooxygenase; DEGs: Differentially expressed genes; GO: Gene Ontology; GST: Glutathione-S-transferase; GT: Glycosyltransferase; KEGG: Kyoto Encyclopedia of Genes and Genomes; MF: Molecular function; NCBI: National Center for Biotecnology Information; NTSR: Non-target site resistance; POD: Peroxidase; qRT: quantitative real-time; RNA-Seq: RNA-sequencing; RPKM: Reads per kilobase million mapped reads; SRA: Sequence read archive; TM: Tribenuron-methyl; TSR: Target-site resistance}

\section{Acknowledgments}

The authors gratefully acknowledge all the workers for assistance in conducting this research. We also thank the Editage for their professional English language editing services.

\footnotetext{
Author details

1 Key Laboratory of Pesticide Toxicology and Application Technique, College of Plant Protection, Shandong Agricultural University, Tai'an 271,018, Shandong, China.

${ }^{2}$ Taian Customs, Taian 271,000, Shandong, China.
}

\section{Funding}

This research was funded by the National Natural Science Foundation of China (No. 31601653, 31772181 and 31471424), the Project funded by China Postdoctoral Science Foundation (No. 2017 M612311), and the Funds of "Shandong Double" Tops Program (No. SYL2017XTTD11).

\section{Availability of data and materials}

The raw Illumina sequence reads of susceptible (S) and resistant (MR) M. aquaticum have been deposited in the NCBI Sequence Read Archive (SRA) database with accession number SRP128620 and SRP128613, respectively. This Transcriptome Shotgun Assembly (TSA) project has been deposited at DDBJ/EMBL/GenBank under the accession GGTY00000000. The version described in this paper is the first version, GGTY01000000.

\section{Authors' contributions}

This study was designed by WTL and JXW. WTL and SB analyzed the sequencing data, performed qRT-PCR validations. The collection of plant materials, dose-response experiments and ALS activity assays were conducted by SB. NZ, SSJ, WL and LLZ provided helpful suggestion in data analysis and manuscript revision. WTL and JXW wrote the manuscript. All authors read and approved the final manuscript.

\section{Ethics approval and consent to participate}

This research did not involve any human subjects, human material, or human data. M. aquaticum in current research did not belong to the endangered or protected species.

\section{Consent for publication}

Not applicable.

\section{Competing interests}

The authors declare that they have no competing interests.

\section{Publisher's Note}

Springer Nature remains neutral with regard to jurisdictional claims in published maps and institutional affiliations.

\section{Author details}

'Key Laboratory of Pesticide Toxicology and Application Technique, College of Plant Protection, Shandong Agricultural University, Taian 271018, Shandong, China. ${ }^{2}$ Taian Customs, Taian 271000, Shandong, China.

Received: 8 February 2018 Accepted: 27 September 2018 Published online: 11 October 2018

\section{References}

1. Délye C. Unravelling the genetic bases of non-target-site-based resistance (NTSR) to herbicides: a major challenge for weed science in the forthcoming decade. Pest Manag Sci. 2013;69(2):176-87.

2. Délye C, Duhoux A, Pernin F, Riggins CW, Tranel PJ. Molecular mechanisms of herbicide resistance. Weed Sci. 2015;63(sp1):91-115.

3. Délye $\mathrm{C}$, Jasieniuk M, Le Corre V. Deciphering the evolution of herbicide resistance in weeds. Trends Genet. 2013;29(11):649-58.

4. Heap I. Global perspective of herbicide-resistant weeds. Pest Manag Sci. 2013;70:1306-15.

5. Powles S. Global herbicide resistance challenge. Pest Manag Sci. 2014;70(9): 1305.

6. Preston C, Mallory-Smith CA. Biochemical mechanisms, inheritance, and molecular genetics of herbicide resistance in weeds. In: Powles SB, Shaner DL, editors. Herbicide Resistance and World Grains. Boca Raton/London/ New York/Washington, DC: CRC Press; 2001. p. 34-71.

7. Powles SB, Yu Q. Evolution in action: plants resistant to herbicides. Annu Rev Plant Biol. 2010;61:317-47.

8. Yu Q, Powles SB. Metabolism-based herbicide resistance and crossresistance in crop weeds: a threat to herbicide sustainability and global crop production. Plant Physiol. 2014;166:1106-18.

9. Heap IM: The International Survey of Herbicide Resistant Weeds. Available at: www.weedscience.com 2018:[accessed July 23, 2018].

10. Yu Q, Powles SB. Resistance to AHAS inhibitor herbicides: current understanding. Pest Manag Sci. 2014;70:1340-50. 
11. Tranel PJ, Wright TR, Heap IM: Mutations in herbicide-resistant weeds to ALS inhibitors. Available at: http://www.weedscience.com. 2018:[aaccessed July, 23, 2018].

12. Délye C, Michel S, Bérard A, Chauvel B, Brunel D, Guillemin JP, Dessaint F, Le Corre V. Geographical variation in resistance to acetyl-coenzyme a carboxylase-inhibiting herbicides across the range of the arable weed Alopecurus myosuroides (black-grass). New Phytol. 2010;186(4):1005-17.

13. Petit C, Bay G, Pernin F, Délye C. Prevalence of cross-or multiple resistance to the acetyl-coenzyme a carboxylase inhibitors fenoxaprop, clodinafop and pinoxaden in black-grass (Alopecurus myosuroides Huds.) in France. Pest Manag. Sci. 2010;66(2):168-77.

14. An J, Shen X, Ma Q, Yang C, Liu S, Chen Y. Transcriptome profiling to discover putative genes associated with paraquat resistance in goosegrass (Eleusine indica L.). PLoS One. 2014;9:e99940.

15. Unver T, Bakar M, Shearman RC, Budak H. Genome-wide profiling and analysis of Festuca arundinacea miRNAs and transcriptomes in response to foliar glyphosate application. Mol Gen Genomics. 2010;283(4):397-413.

16. Deschamps S, Campbell MA. Utilization of next-generation sequencing platforms in plant genomics and genetic variant discovery. Mol Breed. 2010;25(4):553-70.

17. Metzker ML. Sequencing technologies - the next generation. Nat Rev Genet. 2010:11:31-46.

18. Duhoux A, Carrere S, Duhoux A, Delye C. Transcriptional markers enable identification of rye-grass (Lolium sp.) plants with non-target-site-based resistance to herbicides inhibiting acetolactate-synthase. Plant Sci. 2017;257:22-36.

19. Duhoux A, Carrere S, Gouzy J, Bonin L, Delye C. RNA-Seq analysis of ryegrass transcriptomic response to an herbicide inhibiting acetolactatesynthase identifies transcripts linked to non-target-site-based resistance. Plant Mol Biol. 2015:87(4-5):473-87.

20. Gaines TA, Lorentz L, Figge A, Herrmann J, Maiwald F, Ott MC, Han H, Busi R, Yu Q, Powles SB, et al. RNA-Seq transcriptome analysis to identify genes involved in metabolism-based diclofop resistance in Lolium rigidum. Plant J. 2014;78(5):865-76.

21. Gardin JA, Gouzy J, Carrère S, Délye C. ALOMYbase, a resource to investigate non-target-site-based resistance to herbicides inhibiting acetolactate-synthase (ALS) in the major grass weed Alopecurus myosuroides (black-grass). BMC Genomics. 2015;16(1):590.

22. Pan L, Gao H, Xia W, Zhang T, Dong L. Establishing a herbicide-metabolizing enzyme library in Beckmannia syzigachne to identify genes associated with metabolic resistance. J Exp Bot. 2016;67(6):1745-57.

23. Zhao N, Li W, Bai S, Guo W, Yuan G, Wang F, Liu W, Wang J. Transcriptome profiling to identify genes involved in Mesosulfuron-methyl resistance in Alopecurus aequalis. Front Plant Sci. 2017;8:1391.

24. Matzrafi M, Shaar-Moshe L, Rubin B, Peleg Z. Unraveling the transcriptional basis of temperature-dependent Pinoxaden resistance in Brachypodium hybridum. Front Plant Sci. 2017:8:1064.

25. Serra A-A, Couée I, Heijnen D, Michon-Coudouel S, Sulmon C, Gouesbet G. Genome-wide transcriptional profiling and metabolic analysis uncover multiple molecular responses of the grass species Lolium perenne under low-intensity xenobiotic stress. Front Plant Sci. 2015;6:1124.

26. Yang Q, Deng W, Li X, Yu Q, Bai L, Zheng M. Target-site and non-target-site based resistance to the herbicide tribenuron-methyl in flixweed (Descurainia sophia L.). BMC Genomics. 2016;17:551.

27. Liu W, Yuan G, Du L, Guo W, Li L, Bi Y, Wang J. A novel Pro197Glu substitution in acetolactate synthase (ALS) confers broad-spectrum resistance across ALS inhibitors. Pestic Biochem Physiol. 2015;117:31-8.

28. Liu W, Bai S, Jia S, Guo W, Zhang L, Li W, Wang J. Comparison of ALS functionality and plant growth in ALS-inhibitor susceptible and resistant Myosoton aquaticum L. Pestic Biochem Physiol. 2017;142:111-6.

29. Liu W, Wu C, Guo W, Du L, Yuan G, Wang J. Resistance mechanisms to an Acetolactate synthase (ALS) inhibitor in water starwort (Myosoton aquaticum) populations from China. Weed Sci. 2015;63(4):770-80.

30. Christopher JT, Preston C, Powles SB. Malathion antagonizes metabolism-based Chlorsulfuron resistance in Lolium rigidum. Pestic Biochem Physiol. 1994;49(3): 172-82.

31. Preston C. Herbicide resistance in weeds endowed by enhanced detoxification: complications for management. Weed Sci. 2004;52(3):448-53.

32. Beckie HJ, Tardif FJ. Herbicide cross resistance in weeds. Crop Prot. 2012;35:15-28.

33. Nakka S, Thompson CR, Peterson DE, Jugulam M. Target site-based and non-target site based resistance to ALS inhibitors in palmer Amaranth (Amaranthus palmeri). Weed Sci. 2017:1-9.

34. Scarabel L, Pernin F, Delye C. Occurrence, genetic control and evolution of non-target-site based resistance to herbicides inhibiting acetolactate synthase (ALS) in the dicot weed Papaver rhoeas. Plant science : an international journal of experimental plant biology. 2015;238:158-69.

35. Rey-Caballero J, Menendez J, Osuna MD, Salas M, Torra J. Target-site and non-target-site resistance mechanisms to ALS inhibiting herbicides in Papaver rhoeas. Pestic Biochem Physiol. 2017;138:57-65.

36. Chen J, Huang H, Wei S, Huang Z, Wang X, Zhang C. Investigating the mechanisms of glyphosate resistance in goosegrass (Eleusine indica (L.) Gaertn.) by RNA sequencing technology. Plant J. 2017;89(2):407-15.

37. Iquebal MA, Soren KR, Gangwar P, Shanmugavadivel PS, Aravind K, Singla D, Jaiswal S, Jasrotia RS, Chaturvedi SK, Singh NP, et al. Discovery of putative herbicide resistance genes and its regulatory network in chickpea using transcriptome sequencing. Front Plant Sci. 2017;8:958.

38. Leslie T, Baucom RS. De novo assembly and annotation of the transcriptome of the agricultural weed Ipomoea purpurea uncovers gene expression changes associated with herbicide resistance. G3: Genes|Genomes|Genetics. 2014;4(10):2035-47.

39. Peng Y, Abercrombie LL, Yuan JS, Riggins CW, Sammons RD, Tranel PJ, Stewart CN Jr. Characterization of the horseweed (Conyza canadensis) transcriptome using GS-FLX 454 pyrosequencing and its application for expression analysis of candidate non-target herbicide resistance genes. Pest Manag Sci. 2010:66(10):1053-62.

40. Riggins CW, Peng Y, Stewart CN Jr, Tranel PJ. Characterization of de novo transcriptome for waterhemp (Amaranthus tuberculatus) using GS-FLX 454 pyrosequencing and its application for studies of herbicide target-site genes. Pest Manag Sci. 2010;66(10):1042-52.

41. Yang X, Yu XY, Li YF. De novo assembly and characterization of the Barnyardgrass (Echinochloa crus-galli) transcriptome using next-generation pyrosequencing. PLoS One. 2013;8(7):e69168.

42. Iwakami S, Endo M, Saika H, Okuno J, Nakamura N, Yokoyama M, Watanabe H, Toki S, Uchino A, Inamura T. Cytochrome P450 CYP81A12 and CYP81A21 are associated with resistance to two Acetolactate synthase inhibitors in Echinochloa phyllopogon. Plant Physiol. 2014;165(2):618-29.

43. Yuan JS, Tranel PJ, Stewart CN Jr. Non-target-site herbicide resistance: a family business. Trends Plant Sci. 2007;12(1):6-13.

44. Saika H, Horita J, Taguchi-Shiobara F, Nonaka S, Ayako NY, Iwakami S, Hori K, Matsumoto T, Tanaka T, Itoh T, et al. A novel rice cytochrome P450 gene, CYP72A31, confers tolerance to acetolactate synthase-inhibiting herbicides in rice and Arabidopsis. Plant Physiol. 2014;166(3):1232-40.

45. Benveniste I, Bronner R, Wang Y, Compagnon V, Michler P, Schreiber L, Salaün J-P, Durst F, Pinot F. CYP94A1, a plant cytochrome P450-catalyzing fatty acid $\omega$-hydroxylase, is selectively induced by chemical stress in Vicia sativa seedlings. Planta. 2005;221(6):881-90.

46. Hofer R, Boachon B, Renault H, Gavira C, Miesch L, Iglesias J, Ginglinger JF, Allouche L, Miesch M, Grec S, et al. Dual function of the CYP76 family from Arabidopsis thaliana in the metabolism of monoterpenols and phenylurea herbicides. Plant Physiol. 2014;116(3):1149-61.

47. Ohnishi T, Nomura T, Watanabe B, Ohta D, Yokota T, Miyagawa H, Sakata K, Mizutani M. Tomato cytochrome P450 CYP734A7 functions in brassinosteroid catabolism. Phytochemistry. 2006:67(17):1895-906.

48. Xia XJ, Zhang Y, Wu JX, Wang JT, Zhou YH, Shi K, Yu YL, Yu JQ. Brassinosteroids promote metabolism of pesticides in cucumber. J Agric Food Chem. 2009;57(18):8406-13.

49. Iwakami $\mathrm{S}$, Uchino A, Kataoka $\mathrm{Y}$, Shibaike $\mathrm{H}$, Watanabe $\mathrm{H}$, Inamura $\mathrm{T}$. Cytochrome P450 genes induced by bispyribac-sodium treatment in a multiple-herbicide-resistant biotype of Echinochloa phyllopogon. Pest Manag Sci. 2014;70(4):549-58.

50. Wright AA, Sasidharan R, Koski L, Rodriguez-Carres M, Peterson DG, Nandula VK, Ray JD, Bond JA, Shaw DR. Transcriptomic changes in Echinochloa colona in response to treatment with the herbicide imazamox. Planta. 2017;247(2):369-79.

51. Xiang W, Wang X, Ren T. Expression of a wheat cytochrome P450 monooxygenase cDNA in yeast catalyzes the metabolism of sulfonylurea herbicides. Pestic Biochem Physiol. 2006;85(1):1-6.

52. Pan G, Zhang X, Liu K, Zhang J, Wu X, Zhu J, Tu J. Map-based cloning of a novel rice cytochrome P450 gene CYP81A6 that confers resistance to two different classes of herbicides. Plant Mol Biol. 2006;61(6):933-43.

53. Siminszky $B$, Corbin FT, R Ward E, Fleischmann TJ, Re D. Expression of a soybean cytochrome P450 monooxygenase CDNA in yeast and tobacco enhances the metabolism of phenylurea herbicides. Proc Natl Acad Sci U S A. 1999:96(4):1750-5.

54. Siminszky B, Sheldon BS, Corbin FT, Dewey RE. A cytochrome P450 monooxygenase cDNA (CYP71A10) confers resistance to linuron in transgenic Nicotiana tabacum. Weed Sci. 2000;48:291-5. 
55. Didierjean L, Gondet L, Perkins R, Lau SM, Schaller H, O'Keefe DP, WerckReichhart D. Engineering herbicide metabolism in tobacco and Arabidopsis with CYP76B1, a cytochrome P450 enzyme from Jerusalem artichoke. Plant Physiol. 2002;130(1):179-89.

56. Siminszky B. Plant cytochrome P450-mediated herbicide metabolism. Phytochem Rev. 2006;5(2-3):445-58.

57. Brazier-Hicks $M$, Edwards R. Functional importance of the family 1 glucosyltransferase UGT72B1 in the metabolism of xenobiotics in Arabidopsis thaliana. Plant J. 2005;42(4):556-66.

58. Cummins I, Wortley DJ, Sabbadin F, He Z, Coxon CR, Straker HE, Sellars JD, Knight K, Edwards L, Hughes D, et al. Key role for a glutathione transferase in multiple-herbicide resistance in grass weeds. Proc Natl Acad Sci U S A. 2013;110(15):5812-7.

59. Labrou NE, Papageorgiou AC, Pavli O, Flemetakis E. Plant GSTome: structure and functional role in xenome network and plant stress response. Curr Opin Biotechnol. 2015;32C:186-94.

60. Conte SS, Lloyd AM. Exploring multiple drug and herbicide resistance in plants--spotlight on transporter proteins. Plant science : an international journal of experimental plant biology. 2011;180(2):196-203.

61. Rea PA. Plant ATP-binding cassette transporters. Annu Rev Plant Biol. 2007; 58:347-75.

62. Gonzalez-Torralva F, Brown AP, Chivasa S. Comparative proteomic analysis of horseweed (Conyza canadensis) biotypes identifies candidate proteins for glyphosate resistance. Sci Rep. 2017;7:42565

63. Moretti ML, Alarcon-Reverte R, Pearce S, Morran S, Hanson BD. Transcription of putative tonoplast transporters in response to glyphosate and paraquat stress in Conyza bonariensis and Conyza canadensis and selection of reference genes for qRT-PCR. PLoS One. 2017;12(7):e0180794.

64. Song W-Y, Park J, Mendoza-Cózatl DG, Suter-Grotemeyer M, Shim D, Hörtensteiner S, Geisler M, Weder B, Rea PA, Rentsch D, et al. Arsenic tolerance in Arabidopsis is mediated by two ABCC-type phytochelatin transporters. Proc Natl Acad Sci. 2010;107(49):21187-92.

65. Cagnac O, Bourbouloux A, Chakrabarty D, Zhang M-Y, Delrot S. AtOPT6 transports glutathione derivatives and is induced by Primisulfuron. Plant Physiol. 2004;135(3):1378-87.

66. Windsor B, Roux SJ, Lloyd A. Multiherbicide tolerance conferred by AtPgp1 and apyrase overexpression in Arabidopsis thaliana. Nat Biotechnol. 2003;21:428.

67. Han H, Yu Q, Purba E, Li M, Walsh M, Friesen S, Powles SB. A novel amino acid substitution ala-122-Tyr in ALS confers high-level and broad resistance across ALS-inhibiting herbicides. Pest Manag Sci. 2012;68(8):1164-70.

68. Yu Q, Han H, Vila-Aiub MM, Powles SB. AHAS herbicide resistance endowing mutations: effect on AHAS functionality and plant growth. J Exp Bot. 2010; 61(14):3925-34

69. Liu W, Bi Y, Li L, Yuan G, Du L, Wang J. Target-site basis for resistance to acetolactate synthase inhibitor in water chickweed (Myosoton aquaticum L. ). Pestic Biochem Physiol. 2013;107(1):50-4.

70. Liu W, Bi Y, Li L, Yuan G, Wang J. Molecular basis of resistance to Tribenuron in water starwort (Myosoton aquaticum) populations from China. Weed Sci. 2013:61(3):390-5.

71. Grabherr MG, Haas BJ, Yassour M, Levin JZ, Thompson DA, Amit I, Adiconis $X$, Fan L, Raychowdhury R, Zeng Q, et al. Full-length transcriptome assembly from RNA-Seq data without a reference genome. Nat Biotechnol. 2011;29(7): 644-52.

72. Saha S, Sparks AB, Rago C, Akmaev V, Wang CJ, Vogelstein B, Kinzler KW, Velculescu VE. Using the transcriptome to annotate the genome. Nat Biotechnol. 2002;20:508.

73. Finn RD, Clements J, Eddy SR: HMMER web server: interactive sequence similarity searching. Nucleic Acids Res 2011; 39(suppl_2):W29-W37.

74. Petersen TN, Brunak S, von Heijne G, Nielsen H. SignalP 4.0: discriminating signal peptides from transmembrane regions. Nat Meth. 2011:8:785.

75. Krogh A, Larsson B, von Heijne G, Sonnhammer ELL. Predicting transmembrane protein topology with a hidden markov model: application to complete genomes11Edited by F. Cohen. J Mol Biol. 2001;305(3):567-80.

76. Conesa A, Götz S, García-Gómez JM, Terol J, Talón M, Robles M. Blast2GO: a universal tool for annotation, visualization and analysis in functional genomics research. Bioinformatics. 2005;21(18):3674-6.

77. Ye J, Fang L, Zheng H, Zhang Y, Chen J, Zhang Z, Wang J, Li S, Li R, Bolund L, et al. WEGO: a web tool for plotting GO annotations. Nucleic Acids Res. 2006;34(suppl_2):W293-W7.

78. Mortazavi A, Williams BA, McCue K, Schaeffer L, Wold B. Mapping and quantifying mammalian transcriptomes by RNA-Seq. Nat. Meth. 2008;5:621.
79. Love MI, Huber W, Anders S. Moderated estimation of fold change and dispersion for RNA-seq data with DESeq2. Genome Biol. 2014:15(12):550.

80. Storey JD, Tibshirani R. Statistical significance for genomewide studies. Proc Natl Acad Sci. 2003;100(16):9440-5.

81. Young MD, Wakefield MJ, Smyth GK, Oshlack A. Gene ontology analysis for RNA-seq: accounting for selection bias. Genome Biol. 2010;11(2):R14.

82. Schmittgen TD, Livak KJ. Analyzing real-time PCR data by the comparative CT method. Nat Protoc. 2008:3:1101.
Ready to submit your research? Choose BMC and benefit from:

- fast, convenient online submission

- thorough peer review by experienced researchers in your field

- rapid publication on acceptance

- support for research data, including large and complex data types

- gold Open Access which fosters wider collaboration and increased citations

- maximum visibility for your research: over $100 \mathrm{M}$ website views per year

At $\mathrm{BMC}$, research is always in progress.

Learn more biomedcentral.com/submissions 